\title{
Low Dose Of 5-Fluorouracil Combined with A Dendritic Cell Vaccine Delays the Growth of Colorectal Cancer in Mice
}

\author{
Marcela R de Camargo ${ }^{1,2}$, Suzanne Ostrand-Rosemberg ${ }^{3}$, Pedro Vannini and Ramon Kaneno*1,2 \\ ${ }^{1}$ Department of Pathology, School of Medicine of Botucatu, São Paulo State University, Brazil \\ ${ }^{2}$ Departament of Chemical and Biological Sciences, Institute of Biosciences of Botucatu, São Paulo State University Brazil \\ ${ }^{3}$ University of Maryland Baltimore County, USA
}

*Corresponding author: Ramon Kaneno, Departamento de Microbiologia e Imunologia, Instituto de Biociências -

UNESP, Rua Prof. Dr. Plínio Pinto e Silva s/n, Distr. Rubião Júnior, 18618- 691 - Botucatu, São Paulo, Brazil

\begin{tabular}{l}
\hline ARTICLE INFO \\
\hline Received: 幽 August 10, 2020 \\
Published: 幽 August 18, 2020
\end{tabular}

Citation: Marcela R de C, Suzanne Ostrand-R, Pedro V and Ramon K. Low Dose Of 5-Fluorouracil Combined with A Dendritic Cell Vaccine Delays the Growth of Colorectal Cancer in Mice. Biomed J Sci \& Tech Res 29(4)-2020. BJSTR. MS.ID.004826.

\begin{abstract}
We have previously observed that treatment of both human and murine dendritic cells (DCs) treated with ultra-low doses of the antitumor agent 5- fluorouracil (5-FU) improves their maturation/activation and increases the antigen presentation activity. Thus, the present study was designed to evaluate whether the modulatory effects of low concentration of 5- FU combined with DC-based vaccine also occurs in vivo using the experimental model of murine colorectal cancer MC-38 cells. Tumor-bearing C57BL/6 mice were subcutaneously inoculated with syngeneic MC-38 cells and ten days later we started to treat them twice a week with a DC vaccine plus 5-FU. Thirty days after tumor implantation, the tumors were evaluated for the infiltration of MDSC and T cell subsets. Combination of DC vaccine with a low dose of 5-FU induced tumor regression in $77 \%$ of the animals, while progressed in all other control groups. Combinatory therapy also reduced the number of circulating MDSC in comparison with non-treated animals. Our results indicate that low dose 5-FU enhances the therapeutic efficacy of DC vaccine.
\end{abstract}

Keywords: 5-FU Therapy; Colorectal Cancer; Dendritic Cell; Immunomodulation; Vaccine.

Abbreviations: CRC: Colorectal Cancer; 5-FU: 5-Fluorouracil; DC: Dendritic Cells; HVC: High Endothelial Vascular Cells

\section{Short Communication}

Colorectal Cancer (CRC) ranks the 3rd most frequent type of cancer in many developed countries, with estimated 147,950 new cases and 53,200 deaths in 2020 [1]. The standard treatment has been 5-Fluorouracil (5-FU) therapy alone or combined with other drugs, while combination with immunotherapies have also been used $[2,3]$. The potential role of the immune system in limiting the progression of colorectal cancer (CRC) is supported by the finding that patients with CRC who have high numbers of NK, CD4+ and CD8+ $\mathrm{T}$ cells in their peripheral blood or tumor tissue have higher survival rates compared with patients with lower numbers of these cells $[4,5]$. We previously observed that both human [6] and murine Dendritic Cells (DC) [7] sensitized with the lisate of tumor cells exposed to low concentrations of 5-FU, show increased ability to stimulate lymphoproliferation. Similarly, the pre-treatment of tumor cells with low concentrations of paclitaxel, increases their immunogenicity, facilitating the generation of specific cytotoxic $\mathrm{T}$ lymphocytes [8]. The generation of a $\mathrm{T}$ cell antitumor response is highly dependent on the role of DCs and we also have observed that sensitization of human DCs with tumor lysate is enhanced by previous incubation with low concentration of paclitaxel [9]. In addition, we have recently observed that treatment of tumor cells with low concentration of 5-FU in association with pharmacological blockage of autophagy, is able to improve tumor lisates to enhance $\mathrm{DC}$ activity to both improve the potential $\mathrm{T}$ cell responsiveness and 
the specific antitumor response [10]. Then, we were stimulated to investigate the feasibility of in vivo handling of antitumor resistance, combining low dose 5-FU therapy with DC-vaccine.

For the in vitro generation of DC, bone marrow was collected from the tibia and femurs of healthy C57BL/6 male mice. Erythrocytes were lysed with Gey's hemolytic solution and T and B lymphocytes were depleted with anti-CD4, CD8 and B220 magnetic beads (Miltenyi, Inc.). Resulting cells were cultured in complete culture medium supplemented with $80 \mathrm{mg} / \mathrm{ml}$ of both murine recombinant GM-CSF and IL- 4 at $37^{\circ} \mathrm{C}$ in a $5 \% \mathrm{CO} 2$ incubator. After 3 days, non-adherent and loosely adherent cells were harvested, split into 6- well culture plates and also cultured with complete culture medium supplemented with both cytokines. Three days later DC were loaded with tumor cell lysates $(100 \mu \mathrm{g}$ protein/106 cells) and harvested $24 \mathrm{~h}$ later. Control DC were cultured without MC38 lysate and referred as "DC" and those cultured with MC38 lysate are referred to as "VAX". Both VAX and DC preparations contained
CD11c+ cells that expressed CD40, CD86, and MHC class II. These markers were slightly increased in VAX. Macrophages accounted for $\sim 10 \%$ of the total cells.

C57BL/6 mice were s c inoculated in the back with MC-38 cells on day 0 and treated with either PBS, DC or VAX on day 10th and 17th after tumor inoculation. Animals receiving VAX or DC were also treated with a low dose of 5-FU $(20 \mu \mathrm{g} /$ animal $)$ plus folic acid $(1,8 \mathrm{mg} / \mathrm{animal})$ twice a week during 3 weeks. Mice were bled on days 0 and 30, when the animals were euthanized. We observed that 5-FU-VAX combination resulted in significantly reduced tumor growth as compared to PBS-treatment $(\mathrm{p}<0.01)$. Treatments with unstimulated DC, VAX or 5-FU alone resulted in intermediate profile of tumor progression (Figure 1). Despite the discrete improvement on the maturation of lysate-loaded DC it is interesting that the combined administration of 5-FU and vaccine delayed the tumor growth by $70 \%$ of the tumor mass.

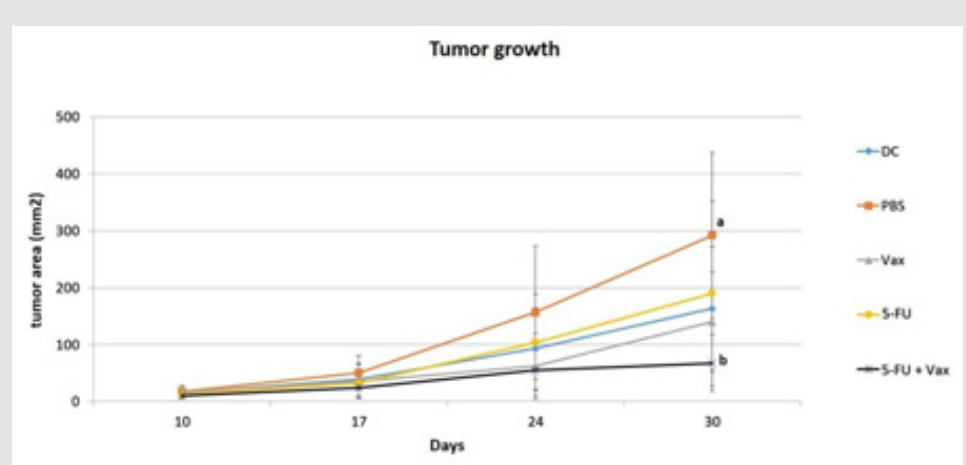

Figure 1: C57BL/ 6 mice were inoculated s.c. with MC38 tumor cells and treated with 5-FU, VAX (tumor lysate-loaded DC), DC (unstimulated DC), 5-FU+VAX), or PBS. Mice were monitored weekly for tumor progression and received 5-FU twice a week. Data were analyzed by ANOVA and Tukey-Kramer Multiple Comparisons Test. $a \neq b ; p<0.01$. N=6.

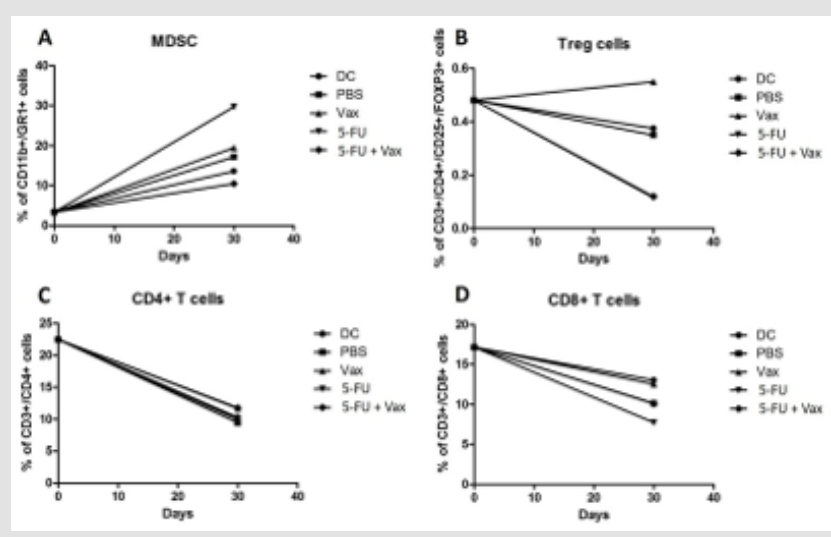

Figure 2:

A. Combinatory therapy reduces the levels of circulating MDSC and

B. Tregs

C. But does not alter CD4 or

D. CD8 T cells levels. Tumor-bearing mice were bled on days 0 and 30 and the circulating leukocytes tested for the percent of MDSC (CD11b+Gr1+), Th (CD3+CD4+), Tc (CD3+CD8+), and Treg (CD3+/CD4+/CD25+/FOXP3+). Statistical analysis made by Dunn and Kruskal-Wallis Test. Data represents the median of two independent experiments; $\mathrm{p}<0.05 ; \mathrm{N}=6$. 
DC vaccines can be hindered by tumor-induced regulatory cytokines and immune suppressive cells that create an antiinflammatory microenvironment [10]. In order to evaluate whether the combinatory therapy altered either pro-tumor or anti-tumor immune cells, circulating leukocytes were obtained at the day zero and at the 30th day of tumor development, and analyzed by flow cytometry for the expression of markers of myeloid- derived suppressor cells (MDSC; Gr1+CD11b+), T regulatory cells (Tregs, CD3+CD4+CD15+Foxp3+), CD4+ T cells (CD3+CD4+), and CD8+ $\mathrm{T}$ cells $(\mathrm{CD} 3+\mathrm{CD} 8+)$. We observed that the levels of circulating $\mathrm{CD} 11 \mathrm{~b}+/ \mathrm{Gr} 1+$ cells increased as tumor progressed (Figure 2A), however, lowest MDSC levels were found in mice treated with the combination of 5-FU and VAX. Interestingly the highest levels of MDSC were observed in mice treated with 5-FU alone. Combinatory therapy also resulted in the lowest levels of circulating Tregs while treatment with VAX alone induced the highest levels of Tregs (Figure 2B). Levels of CD4+ and CD8+ T cells were not changed by none of the treatments tested in this study (Figure 2C \& 2D).
Immunocompetent cells migration and homing is dependent on the expression of L- selectin (CD62L) by leukocytes. L-selectin actively take part in the $\mathrm{T}$ cell homing at lymphoid organs and infiltration into the tumor site [11] so that effector and memory cells differentially express CD62L [12]. Interestingly, both the treatment with 5-FU alone and its combination with 5-FU+VAX increased the percent of CD8+CD62L+ spleen cells (Figure 3). Diverse cells in solid tumors contribute to modulate tumor microenvironment and facilitate tumor progression or regression. Analysis of tumorinfiltrating cells by flow cytometry showed the presence of CD4+ and CD8+ cells, as well as a small proportion of Treg (Figures 4A4C). Treatment with 5-FU and 5-FU-VAX slightly increased the numbers of both CD4 and CD8 lymphocytes. Effective antitumor responsiveness involves migration of immunocompetents cells for the lymphoid organs and further migration of effector memory $\mathrm{T}$ lymphocytes to the tumor site. Such migration and cell homing are dependent on the expression of L-selectin (CD62L) by leukocytes that promotes extravasation from blood to lymphoid organs through the high endothelial vascular cells (HEV) [11,13].

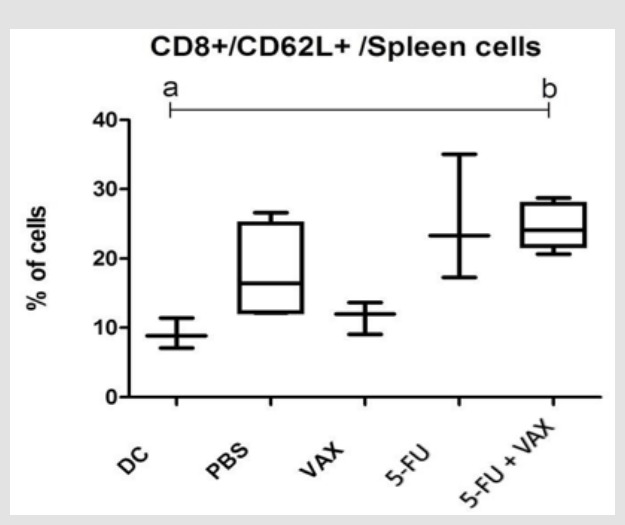

Figure 3: Therapy does not alter spleen content of CD4, CD8, or Tregs, but 5-FU monotherapy and combination therapy increase the level of CD8+CD62L+ cells in the spleen. Mice were euthanized on day 30 and the splenocytes assayed by flow cytometry for CD4, CD8, Foxp3 Statistical analysis made by Dunn and Kruskal-Wallis Test, , $a \neq b ; p<0.05 . N=6$.

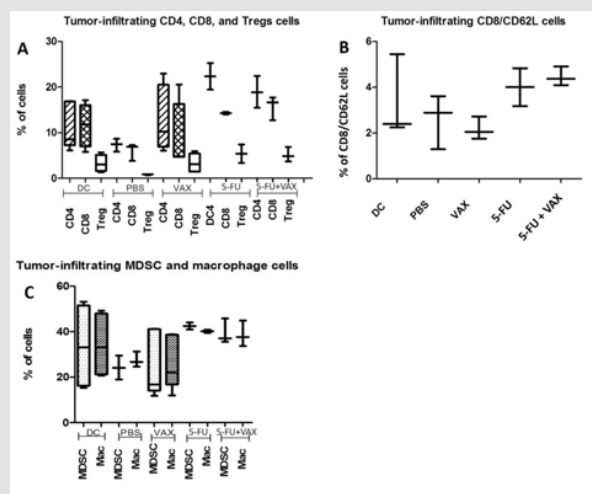

\section{Figure 4:}

A. Phenotype of tumor-infiltrating cells showing the T lymphocytes subsets CD4+T, CD8+T and Treg cells.

B. CD8+ T cells expressing L-selectin (CD62L).

C. MDSC and macrophages. Comparison among all groups on 30th day of experiment. Statistical analysis made by Dunn and Kruskal-Wallis Test, $\mathrm{N}=6$. 
On the other hand, L-selectin also take part in the infiltration of effector memory cells into the tumor site. Here, we observed that expression of L-selectin on CD8+ cells from 5-FU+VAX group is higher than in both DC and VAX groups suggesting that the combination 5-FU+VAX enhances the homing of T cells to lymphoid organs and tumor sites. According to Chao et al, [14] and Raffler et al, [12] murine CD8+ cells stimulated with anti-CD3 antibody presented initial loss of surface L-selectin due to cleavage and all cells became L- selectinlow/negative some days later. Activated cells rapidly divide and differentiate into L- selectinlow/positive effector memory cells that migrate to inflammatory sites. After that, most $\mathrm{T}$ cells undergo apoptosis but some of them evolve into memory cells. Besides that, 5-FU at maximum dose, shows to be contradictory into its ability to favor the immune system and effectively helps downregulating tumor growth [15], suggesting low doses as a good alternative for cancer treatment.

We observed that the numbers of CD4+ and CD8+ circulating cells decreased as the tumor growth, while MDSC increased. Murine MDSC are described as CD11b+/Gr1+ cells, that are hypothesized to originate in the bone marrow of tumor bearing mice $[16,17]$. These cells populate the blood and peripheral lymphoid organs during the tumor growth and enter the tumor site where they play an immunomodulatory/immunosuppressive role $[16,18]$. Tongu et al. [19] observed that combination of low doses of cyclophosphamide and gemcitabine suppressed growing of CT26 colon cancer cells in Balb/c mice. This treatment decreased the percentages of tumorinfiltrating Gr-1high/CD11b+ MDSCs. In accordance with these results, depletion of this population prevents tumor growth in murine models [20]. In our study, contrasting with the findings in peripheral blood, analysis of tumor infiltrating cells showed that both 5-FU and 5-FU+VAX groups have similarly high levels of MDSC. This increased frequency suggests they would have infiltrate the tumor site to induce local modulation, even though the combinatory treatment had delayed the tumor growth. Presence of immuneregulatory elements at the tumor sites, such as FoxP3+ $\mathrm{T}$ cells (Tregs) is closely associated with lower survival, while intratumor CD8+ cytotoxic T cells have favorable clinical outcomes in diverse cancers [21].

Therefore, our results show that combinatory therapy in C57Bl/6 mice was able to delay the tumor growth avoiding the expansion of MDSC cells and increasing CD62L expression on CD8+ cells. We suggest that immunomodulation with 5 -FU can enhance an in vivo tumor-specific immune response against MC-38 response and the association with DC vaccine improves the communication between cells against tumor growth by both activating a $\mathrm{T}$ cellmediated antitumor response and inhibiting immunossupressive cells.

\section{Declarations}

Ethical Approval and Consent to participate: All the proceedings followed the rules of Brazilian College of Animal Experimentation and were approved by the local Ethics Committee (Registration number: 194-CEEA).

Availability of supporting data: The data that support the findings of this study are openly and permanently available in the Department of Chemical and Biological Sciences, Institute of Biosciences, São Paulo State University.

\section{Competing Interests}

Authors declare no conflict of interests.

\section{Funding}

This work was supported by the São Paulo Research Foundation - Scholarship abroad research internship (Fapesp - BEPE) by grant number 2012/17824-3.

\section{Authors Contribution}

MRC performed the experiments, analyzed the results and drafted the manuscript. SOR provided technical and infrastructural support for the study. PV helped to perform the in vitro studies. RK designed the study, analyzed the results, provided technical and infrastructural support, and wrote the final manuscript.

\section{Acknowledgement}

We thank Ms.Virginia Clements for excellent technical support, and PhD. Daniel W Beury, for helping every time during the internship. We also thank Pratima Sinha, Katherine H. Parker, Samuel Haile and Lucas Horn for all support.

\section{References}

1. Siegel RL, Miller KD, Sauer AG, Fedewa SA, Lynn F Butterly, et al (2020) Colorectal Cancer Statistics 2020.CA Cancer J Clin 70(3): 145-164.

2. Tsai Y J, Lin J K, Chen W S, Jiang J K, Teng H W, et al. (2016) Adjuvant FOLFOX treatment for stage III colon cancer: How many cycles are enough? Springerplus 5(1): 1318

3. Mohelnikova Duchonova, B Melichar, B Soucek (2014) FOLFOX/FOLFIRI pharmacogenetics: The call for a personalized approach in colorectal cancer therapy. World J Gastroenterol 20(30): 10316-10330.

4. Qiu H, Xiao Jun W, Zhi Wei Z, Gong C, Guo Qiang W, et al (2009) The prognostic significance of peripheral T-lymphocyte subsets and natural killer cells in patients with colorectal cancer. Hepato-gastroenterology 56(94-95): 1310-1315.

5. Pages F, Kirilovsky A, Mlecnik B, Asslaber M, Tosolini M, et al. (2009) In situ cytotoxic and memory $\mathrm{T}$ cells predict outcome in patients with early-stage colorectal cancer. J Clin Oncol 27(35): 5944-5951.

6. De Almeida CV, Zamame JA, Romagnoli GG, Rodrigues CP, Magalhães MB, et al. (2017) Treatment of colon cancer cells with 5-fluorouracil can improve the effectiveness of RNA-transfected antitumor dendritic cell vaccine. Oncol Rep 38(1): 561-568.

7. De Camargo MR, Gorgulho CM, Rodrigues CP, Penitenti M, Frederico JCL, et al. (2017) Low Concentration of 5-Fluorouracil Increases the Effectiveness of Tumor RNA to Activate Murine Dendritic Cells. Cancer Biother Radiopharm 32(8): 302-308.

8. Kaneno R, Shurin GV, Kaneno FM, Naiditch H, Luo J, et al. (2011) 5 -FU therapeutic agents in low noncytotoxic concentrations increase immunogenicity of human colon cancer cells. Cell Oncol 34(2): 97-106. 
9. Kaneno R, Shurin GV, Tourkova IL, Shurin MR (2009) 5-FU modulation of human dendritic cell function by antineoplastic agents in low noncytotoxic concentrations. J Transl Med 7: 58.

10. Zamame Ramirez JA, Romagnoli GG, Falasco BF, Gorgulho CM, Sanzochi Fogolin C, et al. (2020) Blocking drug-induced autophagy with chloroquine in HCT-116 colon cancer cells enhances DC maturation and $\mathrm{T}$ cell responses induced by tumor cell lysate. Int Immunopharmacol 84 106495.

11. Rosen SD (2004) Ligands for L-selectin: homing, inflammation, and beyond. Annual review of immunology 22: 129-156.

12. Raffler NA R NJ, Ley K (2005) L selectin in inflammation, infection and immunity. Drug Discovery Today: Therapeutic Strategies 2: 213-220.

13. Warnock RA, Askari S, Butcher EC, Von Andrian UH (1998) Molecular mechanisms of lymphocyte homing to peripheral lymph nodes. J Exp Med 187(2): 205-216.

14. Chao CC, Jensen R, Dailey MO (1997) Mechanisms of L-selectin regulation by activated T cells. J Immunol 159(4): 1686-1694.

15. Gmeiner WH (2020) Fluoropyrimidine Modulation of the Anti-Tumor Immune Response-Prospects for Improved Colorectal Cancer Treatment. Cancers (Basel) 12(6): 1641

\section{ISSN: 2574-1241}

DOI: $10.26717 /$ BJSTR.2020.29.004826

Ramon Kaneno. Biomed J Sci \& Tech Res

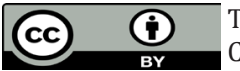

This work is licensed under Creative Commons Attribution 4.0 License

Submission Link: https://biomedres.us/submit-manuscript.php
16. Gabrilovich DI, Ostrand Rosenberg S, Bronte V (2012) Coordinated regulation of myeloid cells by tumours. Nature reviews 12(4): 253-268.

17. Younos IH, Dafferner AJ, Gulen D, Britton HC, Talmadge JE (2012) Tumor regulation of myeloid-derived suppressor cell proliferation and trafficking. Int Immunopharmacol 13(3): 245-256.

18. Zhu XJ, Hu J, Sun L, Xiao Y, Chen ZC, et al. (2013) Amplification of functional myeloid-derived suppressor cells during stem cell mobilization induced by granulocyte colony-stimulation-factor. J Huazhong Univ Sci Technology Med Sci 33(6): 817-821.

19. Tongu M, Harashima N, Monma H, Inao T, Yamada T, et al. (2013) Metronomic chemotherapy with low-dose cyclophosphamide plus gemcitabine can induce anti-tumor $\mathrm{T}$ cell immunity in vivo. Cancer Immunol Immunother 62(2): 383-391.

20. Medina Echeverz J FJ, Zabala M, Ardaiz N, Prieto J, Berraondo P (2011) Successful colon cancer eradication after 5-FUimmunotherapy is associated with profound phenotypic change of intratumoral myeloid cells. J Immunol 2: 807-815.

21. Hodi FS, Dranoff G (2010) The Biologic Importance of Tumor-Infiltrating Lymphocytes. J Cutan Pathol 37(1): 48-53.

$\begin{array}{ll}\text { BIOMEDICAL } & \text { Assets of Publishing with us } \\ \text { RESEARCHES } & \text { - Global archiving of articles } \\ \text { - Immediate, unrestricted online access }\end{array}$

